R. Aschaffenburg et J.-E.-C. Muluen. Journal Dairy Research. 1949, 16, $58,67$.

J. Tramer et J. Wight, Journal Dairy Research. 1950, 17, 194, 199.

J. Wight et J. Tramer. Dairy Indust. 1952, 17, 54, 56.

R. Aschaffen bURg. Dairy Indust. 1953, 18, 316.

G. Thimulin. La Presse Médicale. 1955, n०28, 583 ,

G. Thieulin et D. Basilite, Bul. Acad. Vét. 1955, nº 6 .

\title{
INFLUENCE DU CHAUFFAGE DU LAIT SUR LE DÉVELOPPEMENT DES BACTÉRIES (1)

\author{
Croissance des bactéries lactiques \\ dans des laits chauffés à des températures variables
}

par

J.-E. AUCLAIR et A. PORTMANN

Station Centrale de Microbiologie et Recherches Laitières Jouy-en-Josas

\section{INTRODUCTION}

Il est bien connu que le lait subit, par chauffage, un ensemble de modifications qui le rendent en général plus apte à la croissance des bactéries que l'on y ensemence ultérieurement. On sait en particulier que le lait cru contient des substances bactériostatiques, les "lacténines", qui sont détruites totalement par un chauffage de vingt minutes à $75^{\circ}$.

Les lacténines L1 et L2 sont actives particulièrement sur Streptococcus pyogenes et c'est en utilisant cet organisme que nous avons pu doser ces substances, étudier quelques-unes de leurs propriétés et obtenir enfin des préparations concentrées des lacténines $[1,2,3]$.

En ce qui concerne les bactéries lactiques, il semble bien que les divers phénomènes d'inhibition de ces bactéries par le lait eru, étudiés par de nombreux auteurs [voir par exemple 4, 5, 6, 7, 8, 9] relèvent principalement de l'action des lacténines car les températures et les temps de chauffage généralement cités pour l'inactivation de l'effet inhibiteur du lait eru correspondent assez bien aux conditions thermiques de destruction de ces substances [3].

Il n'est pas impossible cependant que des substances bactéricides autres que les lacténines soient en jeu. D'autre part les résultats de plusieurs auteurs $[4,5,7,10,11]$ suggèrent qu'en dehors de la destruction des substances inhibitrices il apparaît au cours du chauffage du lait, et spécialement aux températures supérieures à $100^{\circ}$, des substances qui ont pour effet de favoriser la croissance des bactéries lactiques.

(1) Annales de Technologie agricole, 1955, no 2, 121. 
OrLa-Jensen et JacobSen [4] ont probablement été les premiers à différencier nettement l'action des substances bactéricides thermolabiles du lait (dont les températures de destruction correspondent à celles des lacténines) de l'effet favorable qu'un chauffage au-dessus de $100^{\circ}$ exerce sur la croissance des bactéries lactiques et en particulier des lactobacilles. Ils attribuaient cet effet activant à la destruction par le chauffage de substances bactéricides thermorésistantes du lait et peut-être, dans une certaine mesure, à des transformations des albumines et du lactose au cours du chauffage. Ces mêmes auteurs remarquaient cependant qu'un chauffage du lait à haute température $\left(115^{\circ}\right)$ pouvait avoir un effet défavorable sur la croissance des streptocoques (Str. cremoris, Str. agalactiae, Str. liquefaciens) et qu'un chauffage encore plus poussé $\left(130^{\circ}\right)$ pouvait avoir également un effet néfaste sur le développement des lactobacilles.

L'action du chauffage du lait à haute température (au-dessus de $100^{\circ}$ ) a été étudiée en particulier par TYLer et WeISer [10] et Foster [11]. Ces auteurs constataient dans l'ensemble, une action favorable du chauffage du lait sur la croissance ultérieure de la plupart des bactéries lactiques utilisées (streptocoques et lactobacilles), mais tandis que les premiers attribuaient ce fait à une baisse du potentiel d'oxydo-réduction du lait au cours' du chauffage, FosTER établissait une corrélation entre l'effet activant du chauffage et l'augmentation de la teneur du lait en azote non protéique, résultant d'une hydrolyse partielle de la caséine. Cet auteur observait de plus, comme ORLA-JENSEN, l'action néfaste que peut exercer un chauffage très sévère du lait sur la croissance ultérieure de certaines bactéries (Str. liquefaciens, Lactobacillus casei).

L'un de nous[12] a signalé à ce propos que le chauffage du lait à l'autoclave pouvait être nuisible à la croissance de Str. agalaciae. Cet effet était attribué à la disparition, à la suite du chauffage, de certains composés sulfurés nécessaires à la croissance de cet organisme et présents seulement dans le lait cru en petite quantité.

Dans les recherches qui vont être décrites, nous avons comparé la croissance d'un petit nombre de bactéries lactiques dans des laits chauffés à des températures variables $\left(60\right.$ à $\left.120^{\circ}\right)$ en vue d'étudier par quelles réactions le chauffage peut dans certains cas, rendre le lait plus favorable au développement de certaines espèces bactériennes ou, au contraire, nuire à la croissance d'autres espèces de microbes.

\section{Méthodes}

Le lait utilisé dans ces expériences a été recueilli par traite aseptique sur des vaches dont les mamelles avaient été reconnues, 
précédemment, exemptes d'infection microbienne. Huit prélèvements ont été faits séparément sur trois vaches de race hollandaise (Pâquerette, Tulipe, Rose) et deux vaches de race normande (Cabale et Badou), appartenant au troupeau laitier du Centre de Recherches zootechniques de Jouy-en-Josas.

Le lait était écrémé dans une écrémeuse préalablement stérilisée à l'autoclave, puis réparti en tubes de $18 \times 180$ millimètres, par fractions de 5 millilitres. Ces tubes étaient ensuite chauffés soit par immersion pendant vingt minutes dans un thermostat réglé à la température choisie à $0^{\circ} \mathrm{l}$ près pour les chauffages à température inférieure ou égale à $100^{\circ}\left(60-65^{\circ}-70^{\circ}-75^{\circ}-80^{\circ}-90^{\circ}-100^{\circ}\right)$, soit par maintien pendant vingt minutes à l'autoclave pour les températures supérieures à $100^{\circ}$, ces températures étant déterminées d'après les indications du manomètre de l'autoclave.

Les tubes de lait ainsi préparés étaient conservés dans une chambre froide ( $-10^{\circ}$ environ) jusqu'au moment de leur utilisation.

Les souches de bactéries utilisées étaient les suivantes : Str. agalactiae 1 B, Str. lactis X 13, Str. lactis 7 M 10, Str. cremoris $1 \mathrm{P5}$, L. lactis 037 et Str. thermophilus TJ.

Chaque souche était, au cours d'un même essai, ensemencée dans 3 tubes de chacun des laits chauffés aux différentes températures. La dose d'inoculation utilisée, variable suivant les souches, avait été choisie au cours d'expériences préliminaires de façon que les cultures des différentes souches en lait stérilisé parviennent à la fin de leur phase logarithmique après 18 heures d'incubation à la température optima de croissance de chacun des organismes.

Après incubation dans un thermostat réglé à la température voulue $\left( \pm 0^{\circ} 1\right)$, le $p \mathrm{H}$ des cultures était déterminé à l'aide d'un $p$ H-mètre à électrode de verre.

Le $p \mathrm{H}$ des cultures après incubation a été choisi comme mesure de l'activité des microorganismes utilisés, car il nous paraissait représenter, pour ces bactéries fortement productrices d'acide lactique, le critérium le plus important de leur activité métabolique. On sait d'autre part, que la production d'acide par les bactéries lactiques est étroitement liée à leur croissance. Enfin, la détermination du $p \mathrm{H}$ offrait, au point de vue pratique, l'avantage d'être très rapide et permettait d'effectuer un grand nombre d'essais en série.

\section{Résultats}

Les figures 1 à 6 montrent l'influence du chanffage du lait sur la croissance ultérieure des six organismes utilisés, L'acidité obtenue dans les cultures après 18 heures d'incubation, est représentée 
en fonction de la température de chauffage du lait. Chaque point représente la moyenne de trois essais simultanés.

Nous observons tout d'abord que, pour un organisme donné, les courbes obtenues avec des échantillons de lait provenant de vaches différentes ou prélevés sur la même vache à des moments différents présentent des allures semblables.

Au contraire, l'aspect de ces courbes varie essentiellement avec la souche de bactéries utilisée, chaque organisme présentant une courbe caractéristique.

Les courbes obtenues avec Str. agalactiae 1 B montrent que la croissance de cet organisme est maxima dans le lait chauffé à $80^{\circ}$, température de destruction de la lacténine L2 [3]. Au-delà de $80^{\circ}$, la croissance de Str. agalactiae diminue à mesure que l'on augmente la température de chauffage du lait.

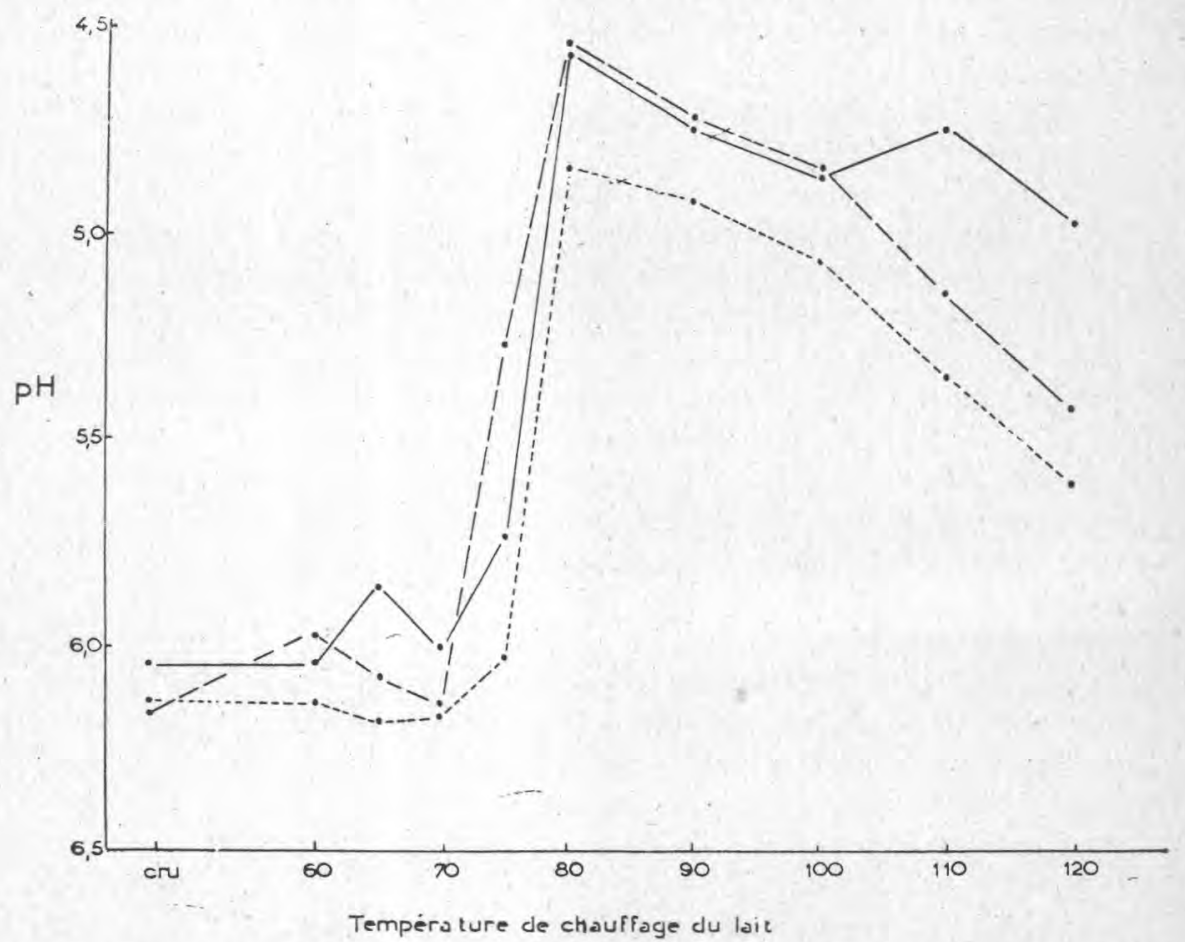

Fig. 1.- Croissance de Streptococcus a galactiae 1 B, dans les laits chauffés à des températures variables.

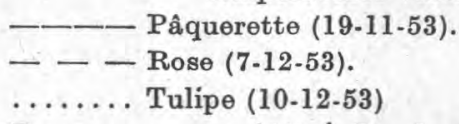

Ensemencement : 1/10 $0^{4}$. Incubation : 18 heures à $37 \circ$. 


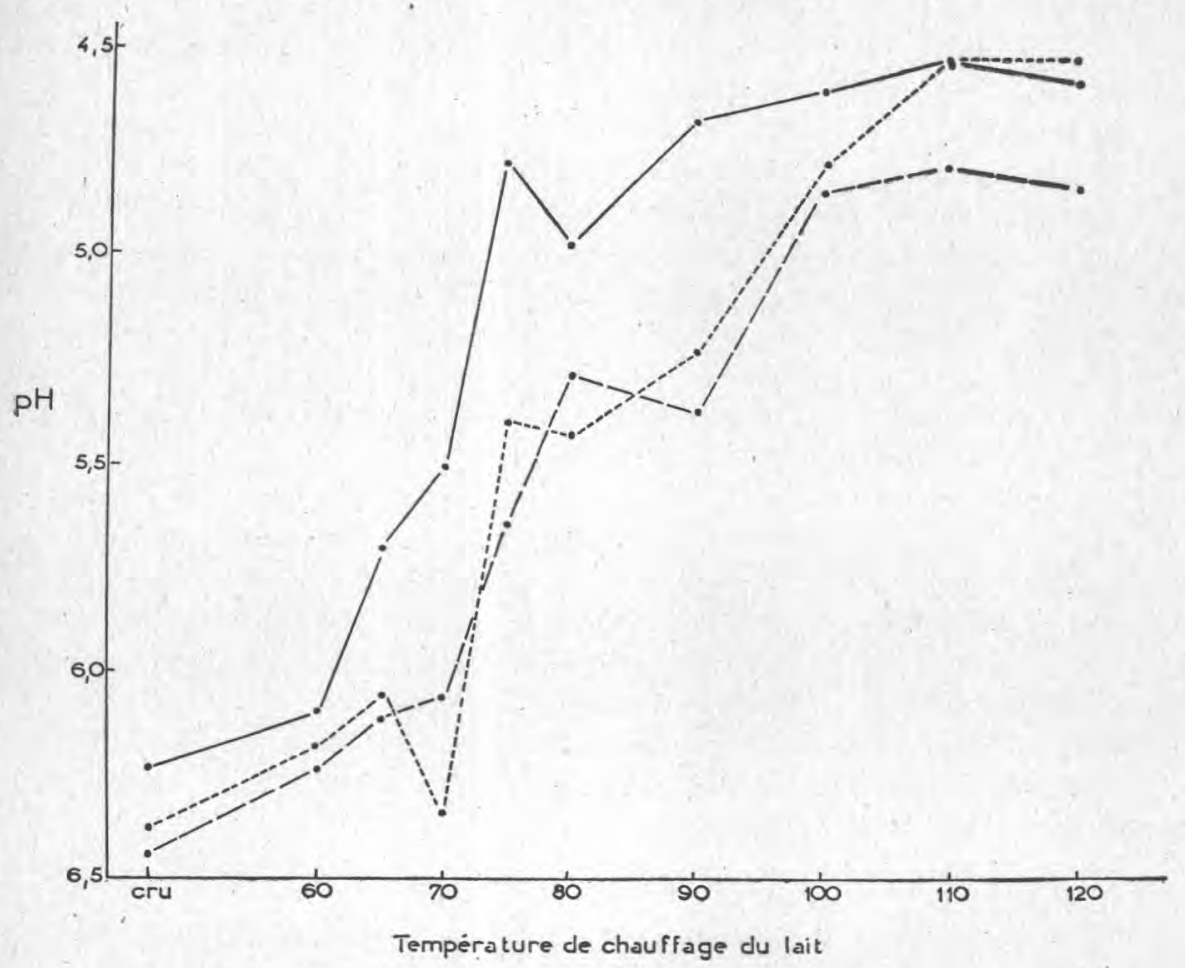

Fig. 2. - Croissance de Streptococcus lactis X 13 dans des laits chauffés à des températures variables.

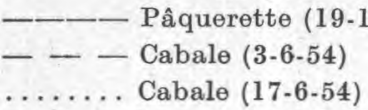

Ensemencement : $1 / 10^{4}$. Incubation : 18 heures à $30^{\circ}$.

$\varepsilon$

Pour Str. lactis X 13, la croissance augmente de façon presque continue lorsque l'on élève la température de chauffage du lait, depuis une croissance faible dans le lait cru jusqu'à un maximum dans le lait chauffé à 110 et $120^{\circ}$. On voit en particulier qu'un chauffage du lait à 60 ou $65^{\circ}$ pendant vingt minutes, qui n'a aucun effet sur les lacténines [3], améliore cependant de façon sensible la croissance de cet organisme.

Str. lactis 7 M 10 montre une croissance à peu près uniforme dans les laits chauffés à différentes températures. Cet organisme en particulier n'est pas sensible aux lacténines.

Str. cremoris 1 P 5 se comporte dans les différents laits de la même façon que Str. lactis X 13. Il présente cependant dans les laits chauffés entre 80 et $100^{\circ}$, une croissance sensiblement diminuée par rapport aux laits chauffés à $75^{\circ}$ et à 110 ou $120^{\circ}$. 
Un minimum de croissance correspondant aux températures de 75 à $90^{\circ}$ est spécialement net pour Str. thermophilus TJ. Pour les températures inférieures à $65^{\circ}$ et supérieures à $90^{\circ}$, la croissance de cet organisme est améliorée par le chauffage du lait.

Les courbes obtenues avec $L$. lactis 037 sont les plus complexes. La eroissance de cet organisme augmente légèrement lorsque l'on chauffe le lait jusqu'aux températures de 70 à $75^{\circ}$, puis brusquement entre 75 et $80^{\circ}$, en même temps que les lacténines sont détruites. Les courbes présentent ensuite un palier entre 80 et $90^{\circ}$, suivi d'une remontée très importante entre les températures de 90 à $110^{\circ}$.

L'augmentation considérable de la croissance de L. lactis 037 à la suite du chauffage du lait au-dessus de $100^{\circ}$ a déjà fait l'objet d'une étude particulière [13]. Nous avons pu montrer que cette augmentation d'activité est due à la formation d'une substance stimulante formée à partir du lactose au cours du chauffage.

Un chauffage prolongé du lait à l'autoclave (plus de 20 minutes à $120^{\circ}$ ) accroît la quantité de substances stimulante formée. Cependant la croissance de L. lactis au lieu de s'en trouver améliorée, diminue au contraire par suite de l'intervention d'un facteur d'inhibition dont l'étude est en cours.

\section{Discussion}

Les résultats qui viennent d'être décrits montrent que le lait subit, par chauffage, des modifications dont les effets sur la crois-

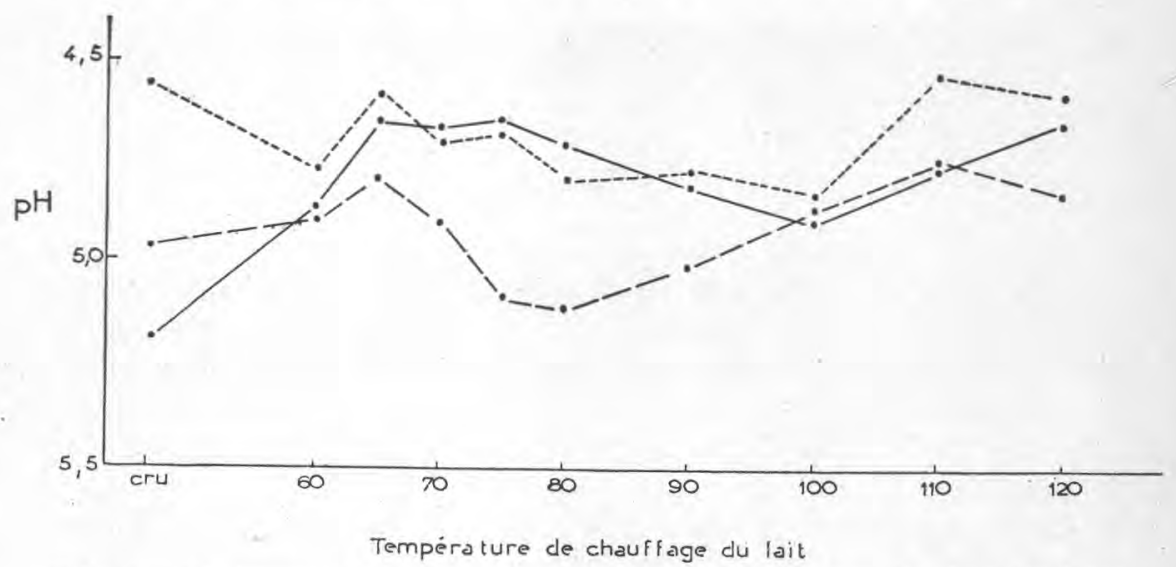

Fig. 3. - Croissance de Streptococcus lactis $7 \mathrm{M} 10$ dans des laits chauffés à des températures variables.

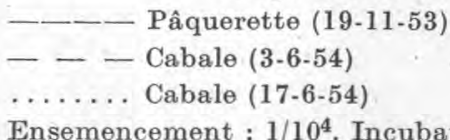

Ensemencement : $1 / 10^{4}$. Incubation : 18 heures à $30^{\circ}$. 


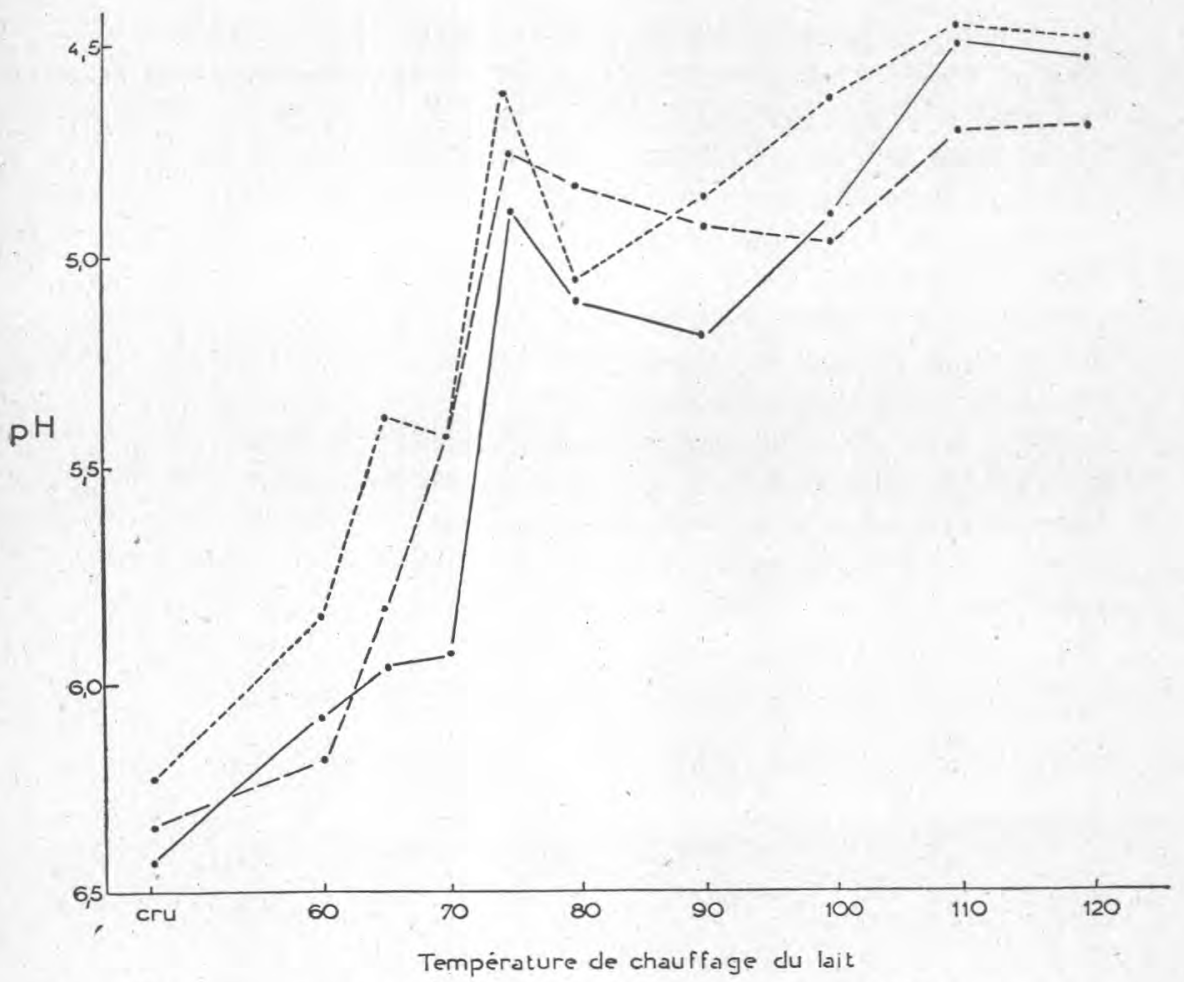

Fig. 4. - Croissance de Streptococcus cremoris 1 P 5 dans des laits chauffés à des températures variables.

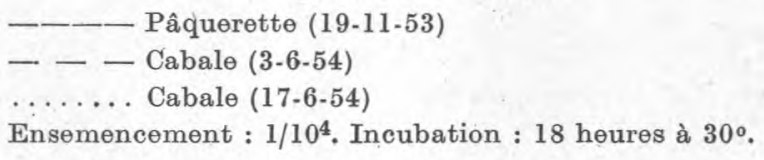

sance des bactéries sont essentiellement variables avec les organismes utilisés. L'augmentation de la croissance des bactéries à la suite du chauffage du lait est un phénomène qui n'est pas général, de même que la destruction des lacténines n'est qu'un des aspects de ce phénomène.

Cependant si l'on considère l'ensemble des courbes obtenues pour les six organismes utilisés, on peut distinguer plusieurs zones de températures où l'on retrouve pour les différents organismes, des effets sensiblement analogues.

Un chauffage du lait pendant 20 minutes à 60 ou $65^{\circ}$ améliore légèrement la croissance de la plupart des organismes essayés.

Dans la zone de température $70-80^{\circ}$, on observe pour quatre organismes : Str. agalactiae $1 \mathrm{~B}$, Str. lactis X 13, Str. cremoris 1 P 5 
et $L$. lactis 0 37, une augmentation brusque de la croissance. Cette zone correspond à la destruction des lacténines (L2 en particulier). Les deux autres organismes, Str. lactis 7 M 10 et Str. thermophilus TJ, ne sont pas sensibles aux lacténines. Str. thermophilus présente a contraire dans cette zone de température et jusqu'à $90^{\circ}$ un minimum de croissance caractéristique.

Le chauffage du lait à des températures supérieures à $90^{\circ}$, augmente la croissance de tous les organismes excepté Str. agalactiae $1 \mathrm{~B}$ pour lequel la croissance diminue à mesure que l'on augmente la température de chauffage.

Dans leur ensemble, ces résultats sont en bon accord avec ceux de ORLA-JENSEN et JACOBSEN [4]. Ces auteurs, utilisant des organismes appartenant aux mêmes espèces que les nôtres, mesuraient l'acidité titrable obtenue après incubation dans des laits chauffés à des températures variables. Les courbes que l'on peut construire

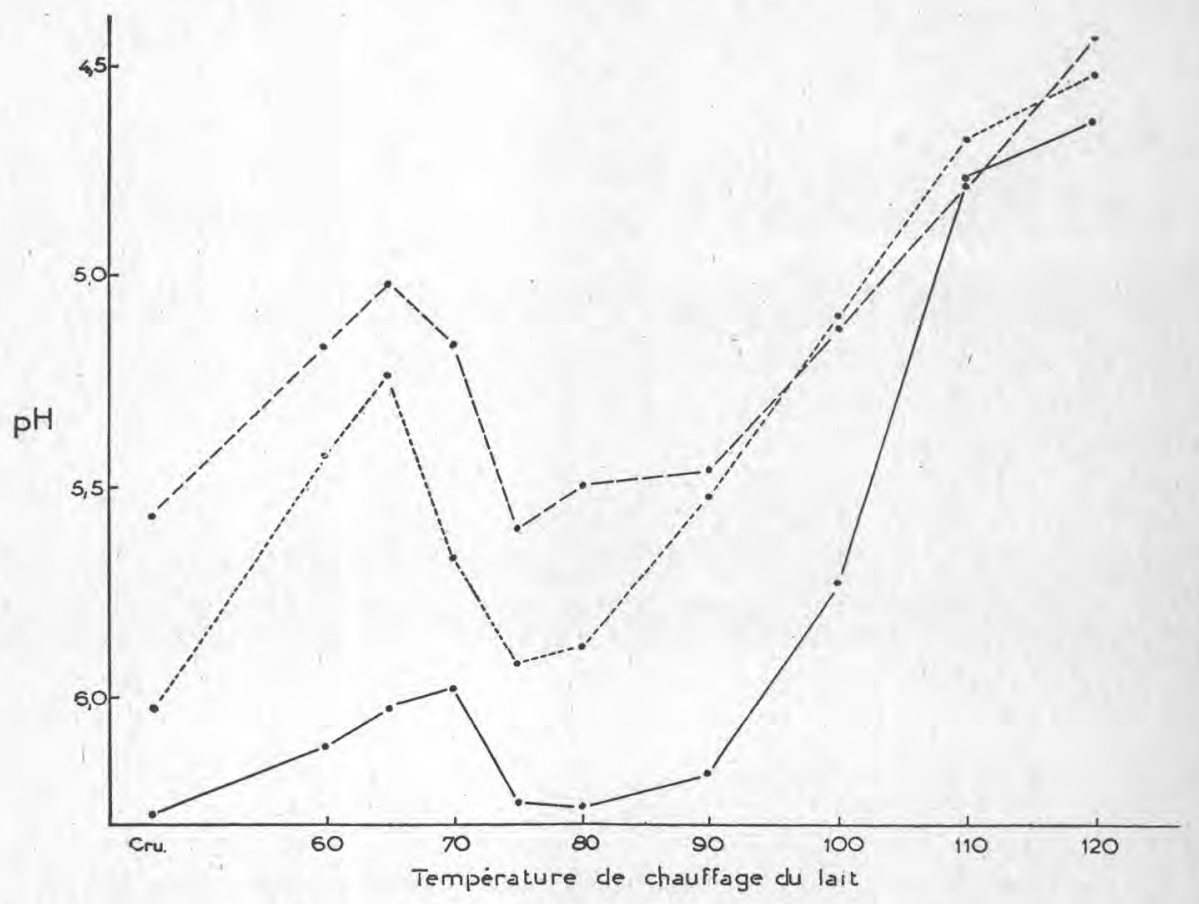

Fig. 5. - Croissance de Streptococcus thermophilus T J dans des laits chauffés à des températures variables.

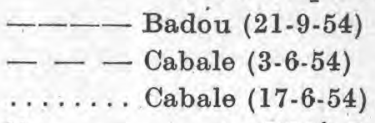

Ensemencement : 1/104. Incubation : 18 heures à $42^{\circ}$. 
à partir de leurs données ont la même allure que celles que nous venons de décrire.

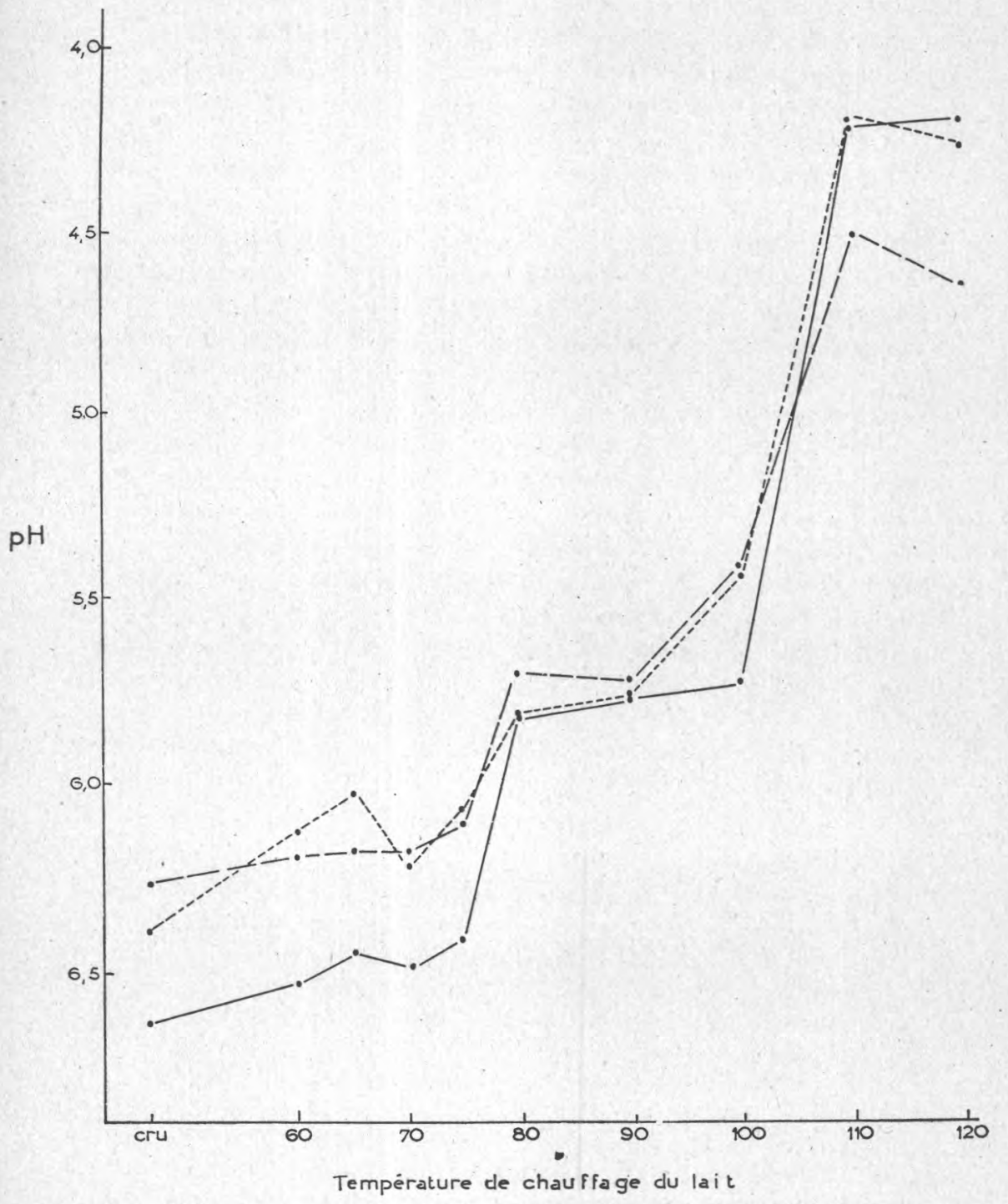

Fig. 6. - Croissance de Lactobacillus lactis 037 dans des laits chauffés à des températures variables.

-- - Pâquerette (19-11-53)

- - Rose (7.12-53)

....... Tulipe $(10-12-53)$

Ensemencement : $1 / 10^{4}$. Incubation : 18 heures à $42^{\circ}$. 
Parmi les modifications que subit le lait au cours du chauffage, nous avons pu reconnaître d'une part la destruction des lacténines dans la zone de température $70-80^{\circ}$, d'autre part, la formation entre 90 et $110^{\circ}$ d'une substance stimulante active spécialement sur L. lactis O 37 [13]. Il est évident d'aprés les courbes obtenues, que d'autres phénomènes interviennent qui restent encore à élueider. Il est possible que l'augmentation de la teneur du lait en azote non protéique, de même que l'abaissement du potentiel d'oxydoréduction du lait au cours du chauffage favorisent le développement de eertains microorganismes $[10,11]$. Cependant, ees phénomènes ne semblent pas avoir une grande influence sur la croissance des organismes que nous avons étudiés ici. Nous n'avons pas pu confirmer non plus la présence dans le lait de substances bactéricides thermostables [4]. Nous avons constaté par contre, comme les autres auteurs $[4,10,11]$, une diminution très nette de la croissance de plusieurs bactéries à la suite du chauffage prolongé du lait à haute température $\left(120^{\circ}\right.$ et au-delà).

Enfin, il est intéressant de remarquer que, si la croissance des micro-organismes dans des laits de vaches individuelles peut, indépendamment de tout traitement thermique, présenter des différences sensibles d'un animal à un autre [14], l'influence du chauffage sur la croissance des bactéries est cependant prépondérante. Cette influence s'exerce toujours de la même manière quelle que soit l'origine du lait; elle dépend avant tout des organismes utilisés, chaque souche bactérienne présentant une réponse caractéristique.

\section{BIBLIOGRAPHIE}

[1] J.-E. Auclair et A. HrRsch. The inhibition of micro-organisms by raw milk. I. The oceurence of inhibitory and stimulatory phenomena. Methods of estimation. Journal Dairy Res., 20, 45-59, 1953.

[2] J.-E. Auclatr et N.-J. Berridge. The inhibition of micro-organisms by raw milk. II. The separation and electrophoretic examination of two different inhibitory fractions. Journal Dairy Res., 20, 370-374, 1953.

[3] J.E. Auctark. The inhibition of micro-organisms by raw milk. III. Distribution and properties of two inhibitory substances, lactenin 1 and lactenin 2. Journal Dairy Res., 21, 323-336, 1954.

[4] S. Orla-Jensen et J. Jacobsen. Neue Untersuchungen uber die bakteriziden Eigenschaften der Milch. Z $b l$. Bak. Parasitenk, II Abt., 80, 321-341, 1930.

[5] P. Ritrer. Einfluss der Erwarmung von aseptisch ermolkener Rohmilch auf das Wachstum der wichtigsten Milchsaurebakterienarten und Esch. Coli. Landw. Jahrbuch der Schweiz, 59, 915-927, 1945.

[6] W. M. Bogdanoff. L'influence des différentes températures de pasteurisation du lait sur le développément des microbes acido-lactiques 
du type Streptococcus lactis et Bacterium casei. Le Lait, 13, 677-686, 1933.

[7] K. Singh et H. Laxminarayana. Studies on the growth of starter organisms in abnormal milk. Indian Journal Dairy Sci., 1, 78-86, 1948.

[8] J. Czulak et J. Meanwell. Seasonal variation in cheese starter activity. Proc. Soc., appl. Pact., 14, 1-6, 1951.

[9] G.-R. JAGo. Factors influencing the lactic acid-producing properties of streptococci used in the manufacture of Cheddar cheese. I. Observations relating inhibitory and stimulatory phenomena. Journal Dairy Res., 21, 111-121, 1954.

[10] M.-E. TyLer et H.-H. Weiser. Factors affecting Swiss cheese starter activity. Effect of heat-treatment and source of milk. Journal Dairy Sci., 25, 939-948, 1942.

[11] E. M. Foster. The effect of heat on milk as a culture medium for lactic acid bacteria. Journal Dairy Sci,35, 988-997, 1952.

[12] J.-E. AUCLAIR. Stimulation of certain bacteria by raw milk. Nature, 173, 491, 1954.

[13] J.-E. Auclair et A. Portmann. Un facteur de croissance pour Lactobacillus lactis, formé au cours du chauffage du lait à l'autoclave. C. R. Acad.Sc., 238, 2463-2465, 1954.

[14] P. Ritrter. Die Disposition der Milch. Landw. Jahrbuch der Schweiz, $63,595-686,1949$.

\section{LAIT PASTEURISÉ - LAIT STÉRILISÉ}

\section{par \\ G. THIEULIN}

Dans l'intérêt primordial de la santé publique et, dans celui, également important, sur le plan social et sur le plan économique, de la production agricole, il est désirable d'accroître considérablement la consommation du lait.

Ce lait doit évidemment être sain et nutritif.

Mais il doit également posséder les qualités gustatives permettant précisément d'en favoriser la consommation.

Sécurité biologique, valeur diététique, qualités organoleptiques : telles sont les propriétés d'un lait officiellement recommandable.

Production satisfaisante, pasteurisation rationnelle, paiement selon la qualité totale : tels sont les moyens de l'obtenir.

Par sécurité biologique, nous voulons entendre "absence de tout danger ", mais pas nécessairement " produit stérile ". Il convient certes de redouter les germes pathogènes, et plus généralement encore, l'action pathogène, mais il nous paraît dangereux d'afficher, par aveuglement, une crainte uniforme du microbe.

L'aliment, en particulier le lait, stérilisé, n'atteint-il pas ce 